\title{
Autorías antropológicas y usufructos legitimadores en los procesos memoriales peruanos a propósito de la Comisión de la Verdad y Reconciliación ${ }^{1}$
}

\author{
Anthropological Authorship and Legitimizing Uses \\ in Peruvian Memorial Processes: The Peruvian Truth \\ and Reconciliation Commission
}

\author{
Santiago Martínez-Magdalena \\ UPNA - FLACSO España
}

\section{RESUMEN}

El conflicto armado peruano (1980-2000) fue asumido institucionalmente mediante la investigación de la Comisión de la Verdad y Reconciliación (CVR) en 2001, acreditando con un Informe final hechos, víctimas y victimarios, y las responsabilidades subsecuentes, así como las recomendaciones y programas de reparación y reconciliación nacional. Intelectuales y profesionales de la Antropología tuvieron un protagonismo muy acentuado en ella, y, antes, en la elaboración analítica de los sucesos in situ mientras iban ocurriendo. Este Informe puede ser considerado un monumento nacional en la reciente historia del Perú, aunque cabe preguntarse si asumió las identidades étnicas victimadas. Por otra parte, la Antropología, dentro y fuera de las instituciones, experimentó usos bastardos en su nombre con el fin de legitimar posiciones distintas, acomodadas a veces en ficciones narrativas encontradas. En este contexto es preciso preguntarse por labor de los intelectuales y la antropología como principios de autoridad y legitimación, y a la Antropología misma como lugar plausible de enunciación política.

Palabras clave: Perú; CVR; Memoria; Autoría antropológica; Antropología como legitimación.

\section{SUMMARY}

The Peruvian armed conflict (1980-2000) was engaged with at the institutional level by the investigations of the Truth and Reconciliation Commission (TRC) in 2001, which produced a Final Report establishing facts, victims and perpetrators, and subsequent responsibilities, as well as reparation programmes and recommendations for national reconciliation. Anthropologists played a key role in the Commission itself and in prior analysis of events as they occurred in situ. This report can be considered a national monument in the recent history of Peru, although it is questionable as to whether it properly acknowledged the ethnic identities of the victims. The use of anthropology was also debased,

\footnotetext{
${ }^{1}$ Este trabajo es una versión renovada del expuesto en el V Simposio Internacional "Memoria, narración y justicia"-Cultura y Justicia, el 18 de diciembre de 2012, en el CCHS del CSIC, Madrid, en la mesa "Cultura y Comisiones de la Verdad", y producto de una estancia de investigación en el IF del CSIC.
} 
both in- and outside the institutions, to legitimize different positions, some of which were adjusted in line with conflicting fictional narratives. This context requires us to question the work done by the intellectuals in question and the very principles of authority and legitimation in anthropology.

Key words: Peru; CVR; Memory; Anthropological Authorship; Anthropology as Legitimation.

\section{REFERENTES DISPUTADOS DE LAS AUTORÍAS ETNOGRÁFICAS}

Las autorías antropológicas (Mayer 1991) trabajan sobre hechos o acontecimientos históricos como empíricos vividos y testimoniados (Andreu 2002), vertiendo narratividades orales en textos de trabajo, y documentando enunciaciones discursivas en disputas memoriales (Del Pino 2003; Theidon 2004; Portocarrero 2004). La memoria histórica puede nutrirse entonces de la antropología, o ésta puede contribuir decididamente a articular etnicidades y narrativas nacionales (Jelin 2001), poniendo en claro además las memorias sojuzgadas (Del Pino 2003). Las producciones etnográficas pueden proporcionar sentidos concretos a poblaciones carentes o necesitadas de ellos; por ejemplo en situaciones de desorientación, crisis o conflictos, como en el caso del conflicto armado peruano entre 1980 y el 2000 (Del Pino 2003). Estas producciones de todos modos son enunciaciones situadas, y pueden estar respondiendo a posiciones académicas, disciplinarias y coloniales/decoloniales concretas (Degregori y Sandoval 2008; Villarías-Robles 2008; Burga 2014). En todo ello, cabe preguntarse por una función legitimadora de la antropología, distinta pero superpuesta a la de la historia (Jelin 2001: cap. 2), por cuanto sus textualidades están apegadas al campo, al testimonio y la presencialidad de la observación en el contexto (Blondet y González en la presentación a la obra de Degregori et alii 1996: 13). Para el caso memorial peruano, se ha discutido largamente el papel legitimador de la antropología y sus perversiones, su trabajo adentro-afuera (intelectuales orgánicos y críticos; descriptores etnógrafos o activistas), su pertinencia o impertinencia política, el estatuto de su autoridad científica, y sus recreaciones pseudo-antropológicas interesadas (Mayer 1991; Del Pino 2003; Rodríguez 2011; Degregori y Sandoval 2008; De la Cadena 2007). De cualquier forma, sí parece claro, como veremos, que la antropología, entre otras ciencias, proporciona rendimientos políticos concretos en el panorama de las interpretaciones y los discursos en las crisis de los Estados-Nación; lo que, ni en su trabajo práctico ni en sus usurpaciones políticas, se resuelve fácilmente en estas discusiones.

Todo esto se hace más agudo cuando el objeto de estudio es la violencia (Degregori 1992; Castillejo 2005; Bolívar y Flórez 2004), el poder en sus distintas formas, las representaciones del sufrimiento y el tratamiento textual de la subalternidad (Del Pino 2003). Tal es así que Rodríguez (2011: 590), para el caso de Perú, discute "las posibilidades de intervención del conocimiento científico en la interpretación de los "hechos de violencia"”. La metodología puede estar comprometida. La descripción etnográfica o el análisis antropológico proyectan sobre la relación contextos-textos el desencuentro que hace de las entrevistas testimoniales encuentros excepcionales o de excepción. Dice Ortiz (2004: 251): “[A]l darnos cuenta de la postura interpeladora [de un sujeto que toma la autoría de su discurso, podemos tener] la necesidad de censurar ese latente impulso jerárquico que aún queda cuando nos referimos a los grupos 
sociales subalternizados, al separar, colonialmente, al sujeto del objeto de investigación... Cuando la relación es de sujeto a sujeto estaremos practicando una relación intercultural democrática"; y antes propone un método: "LLas competencias del mediador de las voces subalternas] pueden continuar pretendiendo "representar" a los "sin VOZ" y por lo tanto hablar en nombre de ellos o, de lo contrario, reconocer que aún no siendo uno de ellos se está o no con ellos; si ocurre lo último, se trata de ejecutar en la relación un movimiento lateral y no vertical" (loc. cit.: 250)2. La posición etnográfica puede estar inscrita en una "industria de la extracción" (Castillo 2005: 5051); y requerir de una sensibilidad ética cuando la información de campo se transforma en testimonial, cuando la antropología habilita la historia, la justicia y la memoria, y es necesario otorgar al informante la condición de "Víctima" (Das 2008: 335).

En nuestro caso, vamos a repasar cómo ha venido operando la antropología y la intelectualidad anexa en los procesos de memoria del Perú contemporáneo, en especial a propósito de la CV/CVR o su entorno. Como es conocido, el conflicto armado peruano (1980-2000) fue acreditado o asumido institucionalmente por medio de la Comisión de la Verdad, más tarde de la Reconciliación (CVR), instaurada en 2001 por el gobierno transitorio presidido por Valentín Paniagua. La CVR editará en 2003 un Informe final como resultado de una prolija investigación (donde intelectuales y profesionales de la Antropología tuvieron un protagonismo muy acentuado), en la que se refieren los hechos, las víctimas, el contexto de la violencia, los victimarios y responsabilidades, así como las recomendaciones y programas de reparación y la reconciliación nacional. Dicho Informe puede ser considerado un monumento nacional en la reciente historia del Perú, puesto que trabaja con aspectos memoriales que afecta a la consolidación de la memoria nacional, sin propiciar quizá la reivindicación de las identidades étnicas victimadas y las posibilidades plurinacionales. Nuestra estrategia discursiva pretende comprobar cómo opera la enunciación antropológica y sus usos bastardos tanto en su compromiso nacional o en su vertiente disgregadora plurinacional, que puede trabajar como principio de autoridad y legitimación. Asumir una u otra dependerá de los obstáculos para integrar en esta labor, como en la CVR, las identidades étnicas victimadas sin reducirse a una cuestión sociológica.

\section{MONUMENTALIZANDO EL INFORME FINAL DE LA CVR}

La historia nacional peruana se ha elevado con una narrativa general a partir de hitos y elementos constitutivos, alimentada en buena parte por la labor de los historiadores, cronistas, literatos, geógrafos y naturalistas, políticos e intelectuales. Todo ello conformando distintos procesos de memoria histórica y contemporánea del pueblo peruano (Rottenbacher y Espinosa 2010), que de todas formas no puede obviar contra-identidades y disputas (Del Pino 2003; Theidon 2004; Portocarrero 2004). Además de íconos históricos como el pasado prehispánico, la independencia ${ }^{3}$, la guerra con Chile, la abolición de los esclavos, el golpe y gobierno de Velasco Alvarado, la hiperinflación a fi-

\footnotetext{
${ }^{2}$ Quiroz (2006) habla también de la necesaria horizontalidad sujeto-sujeto.

${ }^{3}$ Cfr. la crítica de Degregori (2004a: 31) a la importancia fundacional del 28 de julio en el Perú.
} 
nales de los ochenta, etc., ha cobrado gran relevancia el conflicto sociopolítico interno de 1980 al 2000, que supuso casi setenta mil víctimas, mayoritariamente campesinos quechua hablantes (vide infra). Resumir el conflicto armado peruano no es un ejercicio gratuito. La violencia anterior no es tampoco irrelevante (Muñoz, Paredes y Thorp 2009: 10), y existen narrativas distintas y enfrentadas (Orlove 1991) que argumentan causas y, en la época, soluciones. Dar cuenta del mismo supone aceptar textualidades sociológicas, politológicas o historiográficas y ejercer violencia textual: algo más que describir un simple "contexto". Las explicaciones oscilan analíticamente entre atribuciones de violencia estructural contra el campesinado andino y la ideología radical de Sendero Luminoso (Cotler 1993: 16); entre insurgencia, subversión o terrorismo, guerra armada, guerra interna, etc. (Sundström 2010: \4.3); o entre disputas memoriales y estrategias políticas e identitarias (Del Pino 2003; Theidon 2004; Degregori 2004b) ${ }^{4}$. Todas ellas en busca de legitimidades o ilegitimidades desde posiciones enunciativas. Aunque más tarde vamos a desgranar el contexto y los datos aportados por la CVR, adelantamos ahora las referencias a los agentes del conflicto armado peruano, entre los que destaca la subversión, que dará protagonismo a unas zonas rurales tradicionalmente abandonadas (Cotler 1993). Como hecho inaugural podemos citar la tan mencionada madrugada del 18 mayo de 1980, cuando una facción maoísta del Partido Comunista del Perú quema once ánforas electorales en una población ayacuchana el mismo día en que daban lugar las elecciones que devolverían la democracia al país tras la dictadura militar. Surge aquí el protagonismo de Sendero Luminoso (Degregori 1990), en torno a sus cabecillas, el culto al líder y las acciones insurgentes (Degregori 1997). Los gobiernos sucesivos de Belaúnde Terry, Alberto Fujimori y Alan García inician y sostienen la lucha contra Sendero y después el segundo grupo insurgente de mayor relevancia en el ámbito urbano, el MRTA. Fueron suspendidos derechos constitucionales en distintas provincias, y las fuerzas armadas iniciaron una represión considerable con diferentes estrategias en estados de excepción; en tanto los grupos insurgentes atentaron igualmente contra la población civil en las zonas rurales con grandes atentados en las ciudades. La CVR, en su Informe, supondrá una fuente documental inestimable, y distribuirá las responsabilidades correspondientes, que añadiremos más tarde, denunciando la conculcación de los Derechos humanos. Distintos atentados y represiones alcanzarán gran notoriedad (masacre de Accomarca, asesinato de periodistas en Uchuraccay, atentados de Tarata, secuestros y masacres de La Cantuta, Barrios Altos, matanza de Lucanamarca, etc.). La idea de la ausencia del Estado o su incompetencia dio lugar a la respuesta rural autónoma: las Rondas campesinas (Korsbaek 2009; Degregoriet alii, 1996) fueron formas tradicionales de organización comunal, ni necesariamente andinas campesinas ni tampoco en defensa contra la insurgencia o el narcotráfico, puesto que eran instituciones jerarquizadas donde los propietarios tomaron decisiones organizativas en defensa contra los abigeos en las guardanías de haciendas; donde era importante la masculinidad y la experiencia de sus miembros en el servicio militar y el manejo de armas; estando organizados por los tenientes gobernadores, que distribuían a los comuneros como ronderos y solicitaron a las autoridades permisos de armas, servicios policiales y judiciales; y donde podía darse el ejercicio de la justicia amparado en el derecho consuetudinario. Estas formas organizativas respondían a los atropellos y deja-

\footnotetext{
${ }^{4}$ Cfr. los conjugados de Klarén (2007) y Tanaka (2013).
} 
ciones estatales o autogestionaban el ejercicio de la justicia. Surgen en Cajamarca y Piura a finales de los años setenta, y después en todo el país, hasta regularse normativamente como agentes de conciliación y participación política; en respuesta al terrorismo formas menos autónomas fueron instigadas por el gobierno fujimorista (Rondas Campesinas Anti-subversivas o Comités de Autodefensa), principalmente en Ayacucho, el centro y el sur del país (CVR, tomo II, $₫ 1.5)$. En este caso, organizaciones tradicionales o constituidas al efecto asumen en parte la lucha antisubversiva, incentivadas por el gobierno de manera estratégica (subordinadas a las fuerzas armadas) para combatir, en especial, a Sendero Luminoso. Si bien las organizaciones campesinas pudieron ser en el comienzo del conflicto armado sospechosas de colaboracionismo con los grupos subversivos (la lucha senderista estaba argumentada en la liberación de un campesinado refractario $)^{5}$, pronto fueron alimentadas como estrategia paramilitar en estados de excepción o contextos críticos, siendo reconocidas por decretos estatales entre 1991 y 1992 como comunidades de autodefensa. Después de algunas respuestas espontáneas en localidades rurales a la violencia senderista el ejército agrupa a los campesinos en núcleos poblados como mejor modo de combatir al terrorismo (CVR, tomo II, $\mathbb{\$} 1.5$ ). El resultado de todo esto, en fin, miles de muertos, desaparecidos y desplazados, creando una fractura que se sutura conciliatoriamente con la labor de la CVR, pero cuya dimensión no puede discutirse ${ }^{6}$. Aunque enseguida tratemos esto, es necesario remarcar aquí el problema del conteo, las estimaciones estadísticas, etc., sobre una población que, precisamente, no contaba (muchos campesinos no disponían de DNI y huían de los controles, lo que constituyó un serio problema de no-ciudadanía) ni en las disputas sobre los muertos. La propia CVR (2003, Anexo 2. “¿Cuántos peruanos murieron? Estimación del total de víctimas..."; Anexo 3. "Compendio estadístico"; y FAQ Estadísticas CVR) tuvo que explicar con vehemencia la forma de hacer las estimaciones, habiendo concluido: «69,280 personas, dentro de un intervalo de confianza al 95\% cuyos límites superior e inferior son 61,007 y 77,552, respectivamente. Las proporciones relativas de las víctimas según los principales actores del conflicto serían: 46\% provocadas por el PCP-Sendero Luminoso; 30\% provocadas por Agentes del Estado; y 24\% provocadas por otros agentes o circunstancias (rondas campesinas, comités de autodefensa, MRTA, grupos paramilitares, agentes no identificados o víctimas ocurridas en enfrentamientos o situaciones de combate armado)" (2003 Anexo 2, Introducción). Esta primera discusión de todo conflicto es verdaderamente vergonzosa, pero seguramente necesaria, calibrando unas magnitudes que reparten cupos de responsabilidad y cuyo monto total dan el grado de tolerancia ${ }^{7}$.

\footnotetext{
${ }^{5}$ Véase la complejidad de estas interpretaciones, por ejemplo, en Del Pino (2003).

${ }^{6} \mathrm{La}$ antropología, como ciencia avisada y observadora de los hechos sociales, ya debió estar al tanto levantando información (Degregori et alii 1996: 13). No obstante, es preciso recordar distintas tensiones sobre las concepciones esencialistas aún presentes, sobre todo en antropologías nacionales y sus usufructos, y las necesarias prevenciones sociopolíticas y características disímiles. Destaca la controversia de Starn (1991; 1992 y 1994) y Poole y Renique (1992). También podemos mencionar las discusiones sobre la violencia y poder en el Perú por parte del Centro de Estudios Regionales Andinos Bartolomé de las Casas y los debates sobre el problema agrario auspiciados por el Seminario Permanente de Investigación Agraria (vide "Perú: El problema agrario en debate" - SEPIA IV, editado por C. I. Degregori et alii, 1992).

${ }^{7}$ La cantidad de muertos no considerados (sierra) suele suplir a la calidad de las víctimas consideradas (Lima). Theidon y Peralta (2003) recuerdan la equivalencia histórica 8 indios $=1$ criollo.
} 
En un escenario político de transición se constituye la Comisión de la Verdad y, posteriormente, de la Reconciliación (CVR) con el fin de esclarecer responsabilidades. Uno de los objetivos fundamentales, en forma de producto testimonial y asunción institucional de la historia reciente y la desigualdad y abandono de los sectores andinos subalternos, fue el desarrollo exhaustivo de la investigación sobre los hechos pasados, vertiéndose en el Informe Final (2003). Se realizaron además Audiencias Públicas, dando la voz a las víctimas y proporcionándoles un público oyente por la televisión pública y otros medios (CVR, 2003). La CVR organizó ocho Audiencias con víctimas, cinco Audiencias temáticas y siete Asambleas públicas por todo el país, con el testimonio de 422 personas $(\mathrm{CVR}, 2003)^{8}$. Aunque en seguida contextualizaremos más datos sobre estos productos institucionales, cabe preguntarse de antemano si este Informe y los eventos que organizó la CVR para su presentación constituyen un monumento nacional en la reciente historia del Perú (ausente en Casalino, 2008), y en qué forma es un elemento de constitución y reivindicación de las identidades étnicas victimadas: es decir, parece lícito interrogar (así la CVR) acerca de cuál es el lugar del campesinado andino (y no de las naciones indígenas) en la historia patria ${ }^{9}$. Sin embargo, y puesto que esto supera los márgenes de nuestro trabajo aquí, nos es preciso acusar el por qué de esta pregunta desde nuestra posición lectora y escritural. Nuestra condición profesional de la Antropología nos conduce a revisar, en una fraternidad disciplinar, etno- y logocéntrica, y crítica, la labor de la intelectualidad peruana, y en especial la de las ciencias sociales, en la conformación de la monumentalidad memorial institucionalizada en el Perú por medio de la CVR y su Informe y eventos anexos. En todo ello tiene un lugar destacado el concepto de "Víctima", y sus términos confluyentes que la alimentan en un discurso característico en que se amparan las actitudes y prácticas profesionales: Derechos humanos, Estado perpetrador, terrorismo, discriminación y exclusión de grupos subalternos, campesinado, identidades, derechos de autodeterminación, ciudadanía, etc., y que operan desde la dislógica de los testimonios y la sociología de los profesionales ${ }^{10}$. Podemos sospechar que aunque la consignación de las víctimas les pueda otorgar visibilidad, derechos, reparaciones, organización social y agencia política, los procesos de victimización o victimología generados pueden estar operando como un eufemismo. La construcción reificante a partir de los trabajos de la CVR y las disciplinas y profesionales que redactaron el Informe puede estar negando el conflicto étnico, los problemas de las articulaciones plurinacionales y la agencia política y emancipadora de los pueblos y naciones nativos (cuya victimización es histórica y en origen).

El Informe de la CVR (su descripción en Martín Sánchez, 2005, y Salazar, 2008),

${ }^{8}$ Castillejo (2007: 79 ss.) describe el ritual de algunas de ellas.

9 Carlos Iván Degregori (2004a), antropólogo participante en la CVR, aunque reconoce que el Informe muestra la discriminación socio-económica y cultural del Perú, el abandono de las zonas rurales y la debilidad del Estado, insiste en la persistencia de la desestructuración del país, denunciando desigualdades, el desprecio por los pueblos indígenas y el campesinado, las pugnas desequilibradas en la construcción del Estado nacional y las dificultades de alcanzar una ciudadanía plena y pluricultural. Esto se explica porque el Informe de la CVR no consiguió el compromiso firme del Estado para erradicar esta discriminación histórica. Degregori se muestra crítico de su propia labor institucional en la tensión dentro-fuera de las instituciones.

${ }^{10}$ Vide Saunders (2008) para el caso de la CVR sudafricana. 
en sus discursos, constituye un Monumento funerario nacional y finaliza con un epitafio en memoria de los ausentes, imponiendo al Estado y la Nación una serie de requerimientos: El Discurso de Salomón Lerner (presidente de la CVR) entregando el Informe al Estado, lo presenta "Como un mandato de los ausentes y de los olvidados a toda la Nación. La historia que aquí se cuenta habla de nosotros, de lo que fuimos y de lo que debemos dejar de ser. Esta historia habla de nuestras tareas. Esta historia comienza hoy" (Lima, 28 de agosto de 2003, CVR, Discursos). El Informe constituirá un lugar de memoria en forma de un gran relato histórico o Hatun Willakuy (CVR 2008; Martín Sánchez 2005), que alimenta los discursos de cohesión nacional. Se desprende de Salazar (2008), apropósito de Ricoeur (1996 y 2003), que la memoria (oral, popular, de temporalidad vivida, sin periodización concreta, diversificada individual y colectivamente) se reduce en ocasiones al relato histórico (profesional, periodizado, con criterios de verificación, unitario y explicativo) por demanda nacional; al necesitar el Estado-nación, Perú en este caso, explicar (si no disculpar) un "conflicto interno" que había dejado atrás a gran parte de su población. "Conflicto armado interno", señala el Informe de la CVR y su versión abreviada (CVR 2003: Introducción; CVR 2008: 9), negando la "existencia de un conflicto étnico" (CVR 2003, Prefacio; CVR 2008: 4), lo que sociologiza, des-etnificando, el problema.

Por otro lado, el Informe Final de la CVR, como documento contemporáneo, obedece a las consideraciones de producción y difusión mediáticas, por lo que no es posible custodiar un (solo) Informe en la era de la reproductibilidad técnica. Es un objeto físico, institucional, memorial. Recoge la oralidad testimonial revitalizada por la televisión, donde los audiovisuales operan como recursos actuales para el archivo de memoria del pueblo peruano, siendo sus imágenes perdurables en el tiempo e hitos de la historia republicana. Se custodia: "Al término de sus funciones, el acervo documentario que hubiera recabado la Comisión a lo largo de su vigencia, será entregado, bajo inventario, a la Defensoría del Pueblo, bajo estricta reserva de su contenido" (documento de constitución de la CV; CVR, 2003, Antecedentes, art. 7). Está depositado en las Bibliotecas del Perú como ejemplar de registro legal: existiendo también una Biblioteca Virtual del Genocidio en Ayacucho. Aunque se guarda como objeto material, es portable y reproducible. Se custodia solo su contenido (apenas la oficialidad de su formato), aunque se dispute ${ }^{11}$. Se conmemora, y concede identidad nacional. La oralidad de las víctimas se transforma o mediatiza, no sólo como texto compilado, sino en las Audiencias Públicas transmitidas, como presencia tardía del Estado otrora ausente y padre postrero que ratifica sus voces discordantes. El Informe es producto de numerosísimas entrevistas "Sobre el terreno", es decir, en el Ande, en la Sie-

${ }^{11}$ La CVR ostentó la propiedad intelectual del Informe, "todo material escrito, sistematizado o producido por la Comisión o por un miembro o funcionario de ella en el cumplimiento de sus responsabilidades", como forma de control (especialmente ante la opinión pública), siendo así que "los Comisionados no [podían] reproducir parcial o totalmente dichos materiales sin previo permiso escrito del Presidente" (CVR, Compromiso Ético de los Comisionados, punto 7, 2003). Las leyes 27806 y 27927 de la República del Perú dispondrán, a continuación, el estatuto del Informe: «el Informe Final de la Comisión de la Verdad y Reconciliación es de carácter público y puede ser consultado por cualquier ciudadano o persona que lo requiera. Se autoriza la reproducción total o parcial de su contenido, siempre y cuando sea fiel al original y se cite adecuadamente la fuente" (CVR 2003). 
rra "abandonada". Como lugar de campo e investigación: lo que mantiene aún la distancia cognoscente. Si el Informe (Martín Sánchez 2005, y Salazar 2008) responde a la asunción "del proceso, los hechos y responsabilidades de la violencia terrorista y de la violación a los derechos humanos producidos desde mayo de 1980 hasta noviembre de 2000, imputables tanto a las organizaciones terroristas como a los agentes del Estado, así como [a] proponer iniciativas destinadas a afirmar la paz y la concordia entre los peruanos", se operó recogiendo el testimonio de 16.985 personas (CVR, 2003). Esta enorme oralidad unifica en realidad los hechos en una narración coherente y bajo criterios estables que se sobrepone como documento a las voces de los testimonios, y que de cualquier forma consolida como fuente añadida el patrimonio oral nacional donde abrevarán tanto la Antropología como otras ciencias (Espinoza, 2003), como también las portavocías mediáticas (Ortiz 2004: 246) ${ }^{12}$. Aunque las Audiencias públicas han exhibido historias personales como gran drama nacional, representan limitaciones de las narraciones nacionales diversas (Andrews 2007; Castillejo 2007). Allí, en el Informe, hay un trabajo disciplinario, de "lectura" diagnóstica (escucha) y escritura de condensación. Una suerte de indigenismo provisto para "audiencias civilizadas" con la misma función que el teatro político colonial (Vega Bendezú 2011: 127 y 129); donde el indio es un símbolo narrativo y visual de la patria, pero desactivado étnica y políticamente (Flores Galindo 1993 y 2001; Molinié 2004). Por este motivo es necesario atender a que los redactores y miembros de la CVR fueron ilustres personalidades de la intelectualidad peruana (filósofos, sociólogos y politólogos, antropólogos), vinculados a diferentes instituciones (Universidades y Centros de Investigación); juristas, excongresistas y exsenadores; expertos en seguridad nacional; clérigos y miembros de asociaciones civiles y de Derechos humanos. La misma CVR es la iniciativa central (del Estado) sobre la que gravita una política de la verdad y la memoria, prácticamente como "VOz única" (Garretón, González y Lauzán 2011: 79 y 80). "Estructuras estandarizadas" desde el estado para investigar las violaciones a los Derechos humanos, dirimiendo hechos y responsabilidades (así Wilson 2001; citado en Rodríguez 2011: 589). Si las Comisiones de la verdad tienen como "función principal producir un relato histórico que permita hacer una periodización de lo acontecido, hacer justicia a las historias de las víctimas y los protagonistas del conflicto, imputar responsabilidades y establecer programas de reparación", el Informe final de la CVR en Perú dará "importancia a la memoria y su estructuración en un relato organizado en una temporalidad y especialidad concretas" (Salazar 2008: s. p.). Klarén (2007) ejemplifica el problema de las temporalizaciones a partir de la CVR, al hablar de tiempos largos y cortos en la historia peruana con la violencia como eje, conciliando análisis históricos y sociológicos, y cómo la atribución del conflicto a largas crisis estructurales puede suponer la ideología eurocéntrica del conocimiento, si bien no resuelve la cuestión decolonial.

\footnotetext{
${ }^{12}$ Con razón Guerrero (2000:10) habla de los indios cosificados y desactivados como "pueblos testigos" en los proyectos nacionales, donde la etnografía alcanza gran preponderancia: "[L]a opinión pública de los "ciudadanos del sentido común" había llegado al convencimiento (una suerte de consenso nacional entre los sectores dominantes) de que los indígenas constituían poblaciones casi desaparecidas o, en el mejor de los casos — como algunos antropólogos se apuraban por catalogarlas - eran "pueblos testigos" de un pasado ya ido; culturas "fósiles" o comunidades campesinas arrinconadas en remontadas "regiones refugiom. Ribeiro (1977: 115) habla también de los "pueblos testimonios" en el proceso de conquista (citado por Ortiz 2004: 245).
} 
Las narraciones en las Audiencias públicas, y en algunas otras manifestaciones, pudieron liberarse nominalmente del discurso antropológico e intelectual, aunque sin poder escapar definitivamente de su cosificación textual sobre la que trabaja la institucionalización de la memoria. Las memorias estarán siempre en discusión sobre otras memorias; los silencios no son ni comunes entre ellas ni homogéneos, lo que en los rituales memoriales puede significar la expulsión simbólica y retórica de otras en conflicto de legitimidad (Theidon 2004). Es decir, la tensión de las otredades antropológicas está a la base del trabajo memorial: la memoria no resuelve conflictos, sino que los representa en una reconciliación imposible sin que reconozca la equidad real. Porque la CVR representa, después de todo ${ }^{13}$, como redactora (no tanto relatora) del Informe, a los poderes públicos; lugar en el cual se desenvuelve la producción de la verdad a partir del conocimiento disciplinario y académico. Baste recodar las áreas (y, por cierto, metodologías) de trabajo de la Comisión: Proceso nacional de la violencia; Historias regionales; Estudios en profundidad; Secuelas; Salud mental; Patrones de crímenes y violaciones de los Derechos Humanos (CVR 2003, Núcleo de Informe Final; cfr., en sus Antecedentes, los "hechos" de investigación encargados que constan en el decreto de constitución de la CV, art. 3). Además de las profesiones de los Comisionados, la CV pudo contar con "una Secretaría Ejecutiva como órgano de apoyo para el cumplimiento de sus funciones". Ésta "podrá contratar los servicios de profesionales de las diversas ramas científicas necesarias para el correcto desempeño de su mandato, entre los cuales se incluirán abogados, sociólogos, psicólogos, expertos en medicina y antropología forense, entre otros" (CVR 2003, Antecedentes, Documento de constitución de la CV, Disposición adicional primera). La CVR dispuso también de distintos otros recursos, estableciendo una política de la memoria concreta. Garretón, González y Lauzán (2011: 79-80) recogen esto: "[D]urante su mandato y en forma paralela, aunque complementaria a la preparación de su Informe Final, la CVR implementó distintas medidas relativas a la memorialización del conflicto. Entre éstas se encuentra por ejemplo la exposición "Yuyanapaq: Para Recordar", y convenios... [con el Ministerio de Educación o la "Plataforma conjunta de trabajo sobre investigación de fosas comunes".] [U]na vez terminado el mandato de la CVR, gran parte del trabajo del Estado en relación a las memorias sobre el período se ha basado en la difusión del Informe Final de la CVR. Finalmente, este Informe, a su vez, formuló distintas recomendaciones en materia de verdad y memoria, las que luego fueron recogidas en la formulación del Plan Integral de Reparaciones (PIR) a partir del año 2005.

Así pues, el artefacto estatal viene dotado de poderosas fuentes de enunciación ideológica, y cuenta con disciplinas anexas apropiadas. González Echevarría (2000: 9; citado por Quiroz 2006) entiende Latinoamérica como un núcleo narrativo autorizado (notarial), que al ser escrito por la burocracia imperial "conoce" Latinoamérica en sus ilaciones contemporáneas: grandes relatos que van desde el discurso de la ley

\footnotetext{
${ }^{13}$ La Comisión suscribió un Compromiso Ético (CVR 2003) que los desvinculaba de cualquier representación institucional e ideológica (pero no disciplinaria) y apelaba a sus calidades personales y su conciencia; con un "mandato recibido, particularmente de la verdad, la justicia y la reconciliación entre los peruanos"; estableciendo, como Comisión, una unidad ante la opinión pública y las publicaciones de los resultados del Informe (sobre el tratamiento de los medios de comunicación a propósito de la constitución de la CVR vide Zapata Velasco 2010).
} 
levantado en el Archivo de Simancas durante el período colonial, y el discurso científico de los viajeros y naturalistas europeos del siglo XIX, hasta el estudio antropológico (lengua y mito) que cimentará la ideología nacional americana. Aspecto que no estorba a los esfuerzos de una antropología crítica (Degregori y Sandoval, 2008). Pero las narrativas antropológicas se descentran también desde afuera, desde la ficcionalidad de otros discursos. A este respecto es magistral la obra de Julio Ortega Adiós Ayacucho (Ortega 1986 [2007]), donde el muerto itinerante Alfonso Cánepa viaja a Lima, desde su fosa común, a reclamar sus huesos dispersados por la violencia. En este viaje se encuentra con un antropólogo ${ }^{14}$, quien pretende estudiar al primero como alteridad, obteniendo reconocimiento académico (Ortega 1986: 19-22). Cánepa se resiste a ser un objeto de estudio cuando interpela al antropólogo, entablando una discusión resistente al proponer una comparación con el supuesto "diálogo" del padre Valverde con Atahualpa (y, por cierto, con la comisión presidida por Vargas Llosa en la investigación sobre los asesinatos de los periodistas en Uchuraccay que trataremos más adelante $)^{15}$, asimilando al primero con un "científico social" que enjuició al Inca "anticipando su respuesta, y confirmando sus propias ideas" (Ortega loc. cit.: 19; algo que ya concluye la crítica a la investigación historiográfica y social, en De Vivanco 2011: $25)^{16}$. La tenaza antropológica sucumbe en la inversión de las formas: “[Estaba Cánepa] pensando cómo escapar del antropólogo y de la antropología, lo cual es más difícil que escapar de una cárcel limeña" (Ortega loc. cit.). A este propósito explica Quiroz (2006: s. p.):

Al establecer la comparación entre la antropología y la cárcel, critica [Cánepa] el carácter monológico y autoritario del discurso antropológico. Escapar de este discurso indica el deseo de establecer una nueva razón que supere a la razón positivista basada en una relación de implicancia (Sujeto-Objeto) en la que el Yo define (y domina) al Otro. Supone apelar a una razón dialógica basada en una relación horizontal (Sujeto-Sujeto) signada por el diálogo entre los individuos en contacto. Una situación en la que el sujeto diferente no sea considerado subalterno sino simplemente distinto o semejante en la diferencia.

\footnotetext{
${ }^{14}$ No podemos olvidar que la narrativa de Vargas Llosa incluye a personajes antropólogos o etnólogos (Plasencia, 2011), y que Arguedas practicó la disciplina (Landa 2010).

${ }^{15}$ La comparación constructivista que establecerá Vargas Llosa entre su Informe y la verdad ficcionalizada ha sido estudiada por Lund (1999). La búsqueda excusatoria de un supuesto Vargas Llosa post- choca con su liberalismo multicultural y no se aviene a las ficcionalizaciones andinistas de un Arguedas; sin embargo, mantienen ambos problemas tensionales en torno a etnografías ficcionalizadas (Landa 2010; Plasencia 2011; De la Cadena 2007).

${ }^{16}$ Se refiere al requerimiento que el clérigo Valverde hace en Cajamarca (1532) al Inca Atahualpa para someterlo a Dios, desencadenando la incursión española (Vargas-Salgado 2011: 227); un supuesto "diálogo" que representa el conflicto de la élite letrada colonial frente a la oralidad menospreciada de un Atahualpa (Cornejo-Polar 1990) que de todos modos sí disponía de artefactos sígnicos y comunicativos efectivos, no tenidos por análogos ni, por tanto reconocidos (Quispe-Agnoli 2006). Libros como objetos sagrados (la Biblia del requerimiento de Valverde arrojada al suelo por Atahualpa) fueron artefactos culturales de dominación (Quitiáin Peña 2007). Es destacable, a propósito de la oralidad y la escritura, la corrección de Verdesio (2001) a las tesis restrictivas de Mignolo (1995), en las que se igualaban los amoxtllis mexicas como correlato indígena de los libros de los conquistadores. La materialidad de estos artefactos culturales sería análoga como objetos portadores de signos. Esta asimilación impide el estudio de objetos culturales que no tengan comparación posible ni función análoga con los referentes occidentales (Verdesio 2001: 94). Los textos etnográficos y las crónicas de Indias, finalmente, han sido conjeturadas como artefactos textuales (Del Pino 2008: 29-30).
} 
Quiroz (con Mignolo), retomando el diálogo inverso de Alfonso Cánepa con el antropólogo en Adiós Ayacucho, insiste en el sentido decolonial de la epistemología moderna, como también la desubalternización del conocimiento local que supone esta actitud resistente:

\begin{abstract}
De esta manera, podemos afirmar que esta crítica atraviesa los niveles político y epistémico. En primer lugar, cuestiona al Estado peruano (y, por extensión, al Estado moderno), representado por [el Presidente] Belaúnde ${ }^{17}$ criticando el contenido del informe: mientras éste "habla" a través del antropólogo, puesto que valida la versión que sólo asume ciertos excesos de las Fuerzas Armadas; Alfonso plantea una de las críticas más contundentes que se le ha formulado a este Informe: si, como plantea la Comisión, todos somos culpables, no se pueden establecer responsabilidades particulares. Tanto el Estado como las Fuerzas Armadas quedan libres de responsabilidad. En segundo lugar, se socavan las bases de la epistemología moderna (la Antropología y la Historia): El inicial cuestionamiento a la antropología deviene en una crítica de la epistemología occidental al evidenciar que ésta se ha construido en relación a los procesos de colonización. La perspectiva colonial que imaginó al otro americano como un sujeto sin historia es socavada por Alfonso Cánepa, quien, desde su experiencia local, problematiza el discurso historiográfico indicando sus fisuras (su carácter excluyente, silenciador) y la tanatopolítica del Estado moderno: 'la verdadera historia nacional sería este cuento de las variaciones en la matanza en los mataderos de turno. Cada estilo de matar señalaría una época, cada muerto ilustre (...), pero también cada muerto anónimo...' (Ortega op. cit.: 15). La memoria (la historia otra) cuestiona y reescribe la Historia.
\end{abstract}

Cabe preguntarse por tanto por el uso de la antropología en estos procesos, en los que como expertos participan sus profesionales de una "economía de la extracción" de datos testimoniados; donde los testimonios así recogidos acaban formando parte de discursos académicos (Andreu 2002) en los que los testimonios/informadores pierden el control de su palabra, entrando en recontextualizaciones escritas en informes técnicos o monografías y artículos, en procesos de violencia del silenciamiento reinstalada en las prácticas de investigación (Castillejo 2005). No obstante, el compromiso puede desvincularse de todo esto. Carlos Iván Degregori, antropólogo comisionado de la CVR, proporciona una interpretación distinta de lo que habían recogido Vargas Llosa y sus expertos en su Informe (De Vivanco 2011: 25). "Cuando, al mismo tiempo —escribe De Vivanco, loc. cit.: 24-, perspectivas más agudas, como la de Carlos Iván Degregori, mostraban un mundo andino heterogéneo, contradictorio y cambiante. Diferencias ecológicas y regionales. Variaciones en el comportamiento

\footnotetext{
${ }^{17}$ Belaúnde, en cuyo mandato comienza la violencia terrorista, entendía que las tierras nativas eran parte de la República, por lo que debían estar a su disposición (incluso las selváticas) para ampliar los recursos agrarios con que mantener a una población en constante aumento. Dice Mesclier (2001: 548): "El proyecto de colonización de F. Belaúnde se asemeja, no a la explotación del interior por una metrópoli colonial como en el caso de la organización espacial sugerida por E. Romero, sino más bien a la expansión de una nación hacia tierras que le pertenecen según las leyes internacionales, baldías y por colonizar. Dicha expansión se realiza en detrimento de su población nativa, sin capacidad en aquella época de reivindicar sus derechos, al no estar organizada como Estado-nación reconocido. La referencia a las "regiones naturales" por una parte, a las civilizaciones prehispánicas por otra, otorga sin embargo a la iniciativa una apariencia distinta: aparece como fundada sobre una doble legitimidad, la de una geografía y una historia únicas en el mundo".
} 
de los actores de acuerdo a la doble estratificación, étnica y clasista. Modificaciones en el comportamiento de un mismo actor a través del tiempo. Habría que comenzar por preguntarse entonces quiénes son violentos, dónde y cuándo". En efecto, Degregori critica el abandono en que los científicos sociales peruanos tuvieron el estudio de la violencia interna del Perú hasta no hacerse manifiesta (Degregori 1992: 415 ss.). Si bien esto debe matizarse en lo que venimos diciendo, dado que muchos de ellos levantaron información in situ mientras los trágicos sucesos ocurrían; o, en fin, trabajando críticamente las disputas memoriales. Degregori (2004 a) señala las brechas que el conflicto armado supone: injusta distribución de la riqueza y los ingresos; centralismo capitalino y abandono de las provincias (diferencias regionales); discriminación étnico-cultural y racial; desigualdad generacional y de género. Desigualdades persistentes que llevan a Degregori, crítico con la CVR y más con el gobierno y la sociedad peruana, a decir: "En algunos lugares de nuestro país, el conflicto armado interno fue un verdadero Apocalipsis"; "Los campesinos quechuas... sufrieron un holocausto, aunque en la terminología oficial de la CVR aparezca el caso como "ejecución extrajudicial" y como "masacre» (loc. cit.: 24 y 26). Concluyendo amargamente: "En nuestro país se han producido entonces decenas de pequeños holocaustos, hace varios meses que fueron documentados y entregados al gobierno por la CVR y no pasa nada, o pasa muy poco. [El gobierno, los partidos políticos, la ciudadanía, la prensa se centraron sólo en la condición de los terroristas, en si la actuación de las fuerzas de seguridad fue excesiva, o en el tipo de reparaciones.] Muy poco sobre justicia, o sobre las reparaciones simbólicas, que podrían tener gran impacto sin problemas de financiamiento, casi nada sobre las profundas reformas institucionales que son indispensables para que esta historia no se repita" (loc. cit.: 27); para lo que pide una "refundación del Estado en el Perú" con una "ciudadanía plena". La CVR es así un buen punto de partida para la relectura de la historia que funde un nuevo país (loc. cit.: 31). En seguida, Degregori (loc. cit.: 30-31) trae al discurso una idea ${ }^{18}$ que nos parece principal, y que sigue nuestro texto: el Estado como "artefacto cultural" da importancia a rituales y mitos fundacionales, el 28 de Julio especialmente para el Perú. Aunque se celebra la Independencia, no se asocia a la democracia en absoluto, más bien es una fiesta nacionalista donde militares y guerras de independencia son centrales: San Martín, Bolívar, Junín, Ayacucho ${ }^{19}$. Ahora bien, queda pendiente conjeturar el doble papel de Degregori como antropólogo adentro de la CVR, y por tanto auxiliar al Estado, y su crítica anterior y posterior. Su organicidad puede quedar en cuestión, dado que se interroga por lo que en la actualidad es un tema de interés renovado de la antropología crítica, el estudio del Estado y las administraciones públicas (Das y Poole, 2008), asunto por otra parte tradicional de la antropología trabajando e interrogándose sobre las empresas coloniales. Pero su presencia en la CVR sí manifiesta el doble juego y las dificultades de la asesoría antropológica ${ }^{20}$, los debates sobre teoría y práctica, y crítica y plausibilidad política, y la antropología aplicada, en fin. Apuntalar el Estado democrático tras fuerte crisis, aunque una oportunidad

\footnotetext{
${ }^{18}$ Tomada de Joseph y Nugent (1994); aunque a partir de la exposición de Guillermo Nugent en una mesa redonda del IDL en 2003.

19 Ejemplos de la construcción criolla de los héroes nacionales (Alfaro Rotondo s. f.).

${ }^{20}$ En Degregori entre la oportunidad y necesidad de democratizar el país, la importancia de la memoria y el compromiso (Degregori 2004 b).
} 
práctica que puede llevar a valorar logros y decepcionarse en gran parte ${ }^{21}$, es un asunto delicado que pone a la antropología como herramienta y compromiso de difícil cálculo, máximo cuando todo es, estructuralmente, crítico. Sea como fuere, la antropología, junto con otras ciencias, forman parte del aparato experto que configuró la CVR y redactó el Informe (Castillejo 2005). Y esto por varias razones. La oralidad mediatizada de las Audiencias está sometida, bajo la visualidad como un recurso parejo, a la escritura del Informe, deudor logocéntrico. El auditorio limeño no estaba sensibilizado para "leer" un indigenismo no literario. La realidad estaba aquí como empírico sólo cuando se sufre el atentado en la calle Tarata de Miraflores, Lima, o se asesina a Elena Moyano (Burt, 2010), cuando afecta y se encarna (o descarna) la capital. La consciencia (estatal) temprana del conflicto surge a partir del asesinato de varios periodistas en Uchuraccay en 1983 (López Maguiña 2003; Del Pino 2003), aunque no es hasta los atentados de 1992 en Lima cuando es tomada en cuenta por la opinión pública capitalina; a lo que el presidente Belaúnde reacciona enviado una Comisión de investigación presidida por Vargas Llosa que exculpe al gobierno con argumentos academicistas ante la prensa internacional (Cuya 1996: $\int 4.1$; Del Pino 2003); la que incorporó anexos de asesores antropólogos, lingüistas, psicoanalistas y juristas (posteriormente la CVR recoge otro informe de otro historiador y antropólogo: Del Pino 2003). La atribución de la perpetración de los asesinatos recayó sobre los campesinos, acusados en procesos judiciales posteriores muy confusos (1983-1988; aunque se criticó la inconstitucionalidad y usurpación de poderes de la Comisión Vargas Llosa), no siendo hasta el 2002 con la CVR que se recuerda a los muchos campesinos asesinados y desplazados en el lugar, ampliando y recontextualizando el primer informe (CVR 2003, V, 2: \2.4). La propia CVR reconsideró la interpretación de lo sucedido en el Informe de Vargas Llosa denunciando sus excesos y errores, Informe que partía de la mirada de un indigenismo elitista que atribuía fiereza étnica a los campesinos (Cuya loc. cit.; De Vivanco 2011: 23), cuyas representaciones histórico-antropológicas fueron argüidas por las autoridades académicas confirmando violencias intrínsecas y estructurales a la población andina, diferencias interétnicas por verticalidad ecológica (indianidades sucesivas en cada piso ecológico), rechazo violento de lo foráneo, alteridad jurídica consuetudinaria o extra-nacional, sin conciencia de ciudadanía nacional peruana (así la asesoría del jurista del Informe; en CVR, loc. cit.: 153). Mundos irreconciliables de la ruralía frente a la ciudad, la superstición y la barbarie contra el progreso y la civilización, o a injerencias extranjeras no locales, en referencia a las doctrinas comunistas que amenazaría la armónica unidad comunal (así en los informes antropológicos de la Comisión presidida por Vargas Llosa; crítica sistematizada en Del Pino 2003) y cuya atribución de atavismo e irredentismo andino fue criticada por la misma CVR (2003, loc. cit.: 151-152). Degregori resume la poco afortunada asesoría antropológica del Informe presidido por Vargas Llosa: «Los informes antropológicos buscaron] compensar lo sumario de la investigación en la comunidad con el vasto conocimiento general de los autores sobre el mundo andino. El resultado final fue una visión erudita, pero que hacía de Uchuraccay un compendio coherente y paradigmático, ilustrativo de lo que los antropólogos entendemos como

${ }^{21}$ Cfr. las semblanzas de Degregori en el monográfico "El legado de Carlos Iván Degregori" (VV. AA., 2011). 
"Sociedad andina", subestimando las relaciones de los comuneros con la sociedad nacional y su conocimiento de la coyuntura de guerra que se vivía en la región" (Degregori loc. cit.: 416; Del Pino 2003). Mayer (1991) critica la supuesta legitimidad antropológica de este informe y la necesidad de garantizar una verdadera igualdad jurídica. Queiroz (2006: s. p.) lo pone en relación con la obra literaria de Vargas Llosa, que estaría representando la realidad histórica (Lund 1999), siguiendo a Vich (2002) y Rowe (1996), desde un lugar de enunciación autoritaria: "Esta perspectiva está signada por un carácter monológico, criollo, letrado, etnocéntrico [más tarde etnocida] y colonizador destinado a remarcar la alteridad para utilizarla como una estrategia de dominación. Indica que estos rasgos ya habían sido expresados claramente en el cuestionado informe sobre la matanza de los periodistas en Uchuraccay". De Vivanco (2011: 22-23), por último, criticado esta realidad que no es otra que ficticia, señala cómo el Informe de Vargas Llosa "sobredeterminó la interpretación de la violencia con consideraciones esencialistas. En otras palabras, razones antropológicas o etnográficas ${ }^{22}$, así como naturalistas, fueron levantadas para explicar la violencia en desmedro de razones históricas o políticas, lo que retardó el entendimiento del conflicto y permitió, consecuentemente, el agravamiento de la violencia". No obstante, como sentencia el Informe de la CVR $(\mathrm{V}, 2, \mathbb{\Omega} 2.4)$, el esencialismo paternalista estaba y está en toda la sociedad peruana, en el Estado y sus organismos, en la judicatura, en la prensa, en la academia, en la ciudadanía (incluso en las conmemoraciones de la matanza, en Theidon y Peralta 2003 $)^{23}$. Albergando en especial un fuerte autoritarismo. Baste recordar como ejemplo la pregunta (sobre el terreno) de Vargas Llosa a los acusados del asesinato de los periodistas en el Informe de Uchuraccay: "[Después de escuchar demandas en quechua.] - (Mario Vargas Llosa): ¿Qué otros asuntos quisieran que habláramos, qué otras cosas quisieran que le dijéramos al Presidente? [O, más adelante:] - (Mario Vargas Llosa): El Presidente quisiera saber..." (CVR 2003, V, 2, \2.4: 152); máxime cuando esta Comisión era inconstitucional e incurrió en usurpación de poderes jurídicos (recogido así en el juicio posterior, CVR 2003, V, 2, \ 2.4: 168, n. 140), por lo que no representó al pueblo peruano.

\section{3. ¿IDENTIDADES CULTURALES MOTORIZADAS A PARTIR DEL INFORME FINAL DE LA CVR?}

Como el mismo Degregori (2004 a: 25) recoge, algunos capítulos del Informe de la CVR (2003, I, cap. 3: 163 ss.) comienzan con, y recogen, significativas expresiones de las víctimas: "Mi pueblo era pues un pueblo, no sé..., un pueblo ajeno dentro del Perú"; "Ojalá que de acá a veinte años podamos ser considerados peruanos". Una demanda hacia el Estado, pero también hacia la historia en un no olviden que noso-

\footnotetext{
${ }^{22}$ Aquí funcionando como legitimadoras de la ficcionalidad general sobre lo andino: es decir, la ciencia de una creencia.

${ }^{23}$ Las polémicas iniciadas por Starn, que antes citamos, serían graves en la antropología profesional, pero dada la previsiblemente poca injerencia de la disciplina en la sociedad, quizá no sea tan responsable de sus usos bastardos, puesto que es fuente de otros intereses. La función vigilante de sus producciones sí es tarea de la disciplina.
} 
tros también existimos ${ }^{24}$. Es necesario comprender Uchuraccay, por ejemplo, dentro de un plano memorial en disputa (Theidon y Peralta 2003). Del Pino (2003) repasa los juegos políticos de memorias y contramemorias dentro del papel asignado a la intelectualidad, la academia y la antropología. Denuncia la preeminencia de estos discursos y rendimientos esencialistas en cierta antropología, en detrimento de las memorias de los uchuraccaínos retornados, discursos que también son estratégicos ${ }^{25}$. Las memorias disputadas pueden estar repitiendo, en una forma de traslado, los mismos problemas no resueltos de la tensión esencializadora rural-urbano, tradición-modernidad. Los movimientos étnicos en Perú han sido escasos y difíciles, al menos de manera comparativa, y negados por la propia CVR, como señalamos. El proceso de cholificación devendrá en su lugar como explicación sociológica, presente y dinámico en la gran Lima. Escribe Quijano (2006: 19):

\begin{abstract}
Ese proceso de des-indianización fue abrupto y masivo, abarcó a todo el país, y produjo una población — sobre todo urbana, pero también rural- a la que dentro de la cultura señorial-criolla se le impuso el nombre de "chola". La des-indianización produjo, así, una "cholificación" de la población. Esa población identificada por los otros como "chola" fue sin duda el mayor agente del cambio en la sociedad y el poder en el Perú después de la Segunda Guerra Mundial, aunque primero fue contenida y derrotada políticamente, comenzando con los sucesivos regímenes militares que se autodenominaron revolucionarios, y después en buena parte fue cooptada por el patrón de poder post-oligárquico, en especial desde la re-privatización del control del Estado y la profunda reconcentración del control de los recursos de producción y de los ingresos, que comenzó con la funesta dictadura fuji-montesinista.
\end{abstract}

No des-indianizarse acarreará en buena parte ser objeto de la violencia (así el mismo Quijano loc. cit.: 19-20). El propio gobierno intentará vehiculizar las posibles reindianizaciones para desactivarlas, como en el caso del presidente Alejandro Toledo (De la Cadena 2001) a través de su esposa, ventrílocuo e infructuoso. La Antropología alcanza aquí el máximo cargo político y representacional, nada menos que como consorte del poder y la presidencia, que quiere ejercitarse como voluntad política. Una Antropología "Primera dama" con una presidencia, en la CONAPA, consorte, social, lo que habla por cierto de poder y género, representando al país narrativo e (in)integrable. Esta suerte de práctica pseudo-antropológica actúa aquí como recurso interpretativo del país, y aglutinante político que moviliza a partir del manejo de los símbolos. La antropóloga Eliane Karp de Toledo presidió la Comisión Nacional de Pueblos Andinos y Amazónicos (luego reabsorbida ministerialmente) con el fin de mantener una mesa de diálogo para la prevención de conflictos, con representación paritaria de indígenas y delegados ministeriales, marcando una agenda de inclusión, y pretendiendo una multiculturalidad efectiva dentro de un modelo neoliberal (Pajuelo

${ }^{24}$ Expresión de un testimonio en una audiencia de la CVR (Castillejo 2007: 83 ss.).

25 Del Pino (2003: s. p) entiende que los uchuraccaínos retornados han pergeñado al menos dos memorias diferentes y estratégicas: ante las interpelaciones recurrentes de los foráneos sobre la matanza de los periodistas "inventan" explicaciones basadas en la atribución de ignorancia de sus antepasados (inventar historias era mejor solución que guardar silencio, asumiendo estigmas y posicionándose ante el Perú y el mundo); hacia el interior la memoria era homogeneizadora de la comunidad, superando los conflictos antiguos de los antepasados en el cambio generacional. Cfr. Theidon y Peralta (2003). 
Teves 2006: 70 ss.). Karp redactó textos para el debate nacional y la reforma constitucional (2003) que incluyera a los indígenas en una nueva nación (2002). Sin embargo, la CONAPA fue entendida como un retroceso por el excesivo protagonismo de la primera dama, la corrupción, etc. (Raymond y Arce 2011; Pajuelo Teves 2006: 74 ss.). El cambio de lo folklórico por lo inclusivo entraba dentro de un modelo desarrollista general interesado en la «inclusión" indígena por ausencia. En las elecciones que ganó su marido colaboró activamente en el uso político de simbología andina, dando discursos en quechua (Raymnod y Arce 2011), lo que ha sido denunciado como "canibalismo cultural" (Roncalla 2002): "[Y]a que la plataforma de la indianidad y la choledad han sido utilizadas por Toledo y Karp, es necesario iniciar la crítica del amor colonial entre Eliane Karp y Toledo donde es claro que con el trasfondo de lo indígena ambos se dirigen a la apropiación del capital cultural del otro [europeo y andino]".

Por otra parte, las víctimas, asociadas, habrían estado llamadas a ser quizá un foro de concientización étnica, dada la mayoría de casos de esta condición; más allá o estando así activadas/desactivadas como víctimas en los espacios de representación (Tejero Tabernero 2014). Oelschlegel (2006: \ 6.2), en su revisión sobre el cumplimiento de las recomendaciones de la CVR, menciona la fragmentaria y desigual labor de las asociaciones de víctimas de la violencia interna. Citando el Mapeo de las organizaciones de afectados por la violencia política en el Perú redactado por Oxfam (2004), recoge la relativa importancia de distintas asociaciones regionales, provinciales y distritales, de jóvenes, mujeres, desplazados y víctimas; generadas a partir de los trabajos de la CVR, al amparo del Programa de Apoyo al Repoblamiento y Desarrollo de Zonas de Emergencia, o bien por iniciativas cívicas (OO.NN.GG.). En este caso, la dependencia económica hace que muchas actividades queden fragmentadas o inacabadas. Estas asociaciones están constituidas por todo tipo de víctimas, presos, desplazados, torturados, viudas, huérfanos y familiares de desaparecidos y asesinados extrajudicialmente; la mayoría de sus miembros son mujeres (70\%) en situación precaria. Estas características las hace personas con distintas "problemáticas" (así Oelschlegel, loc. cit.: 1361) que no pueden quedar simplemente en necesidades psicológicas o sociales. La mayoría de las organizaciones, señala este autor, tiene como propósito cubrir necesidades básicas: educación, salud, vivienda, empleo, salir de la pobreza; buscando espacios de alivio y acompañamiento. Su participación política puede ser controvertida (con acusaciones distintas y desdén). Pero cabe preguntarse por la evaluación de los requerimientos de la CVR. Garretón, González y Lauzán (2011: 79-80) recuerdan cómo "algunas organizaciones de derechos humanos han analizado el proceso transicional en el Perú a través del nivel de cumplimiento de las recomendaciones de la CVR ${ }^{26}$. Las víctimas han logrado aportar propuestas de reparación a la CVR, y organizar foros y pronunciamientos ante distintas instancias del Estado, aspirando "al fortalecimiento de sus organizaciones, a la consolidación de sus bases, a su articulación regional y nacional y a su visibilización como población afectada" (Oelschlegel, ibid.). La cuestión étnica aquí sigue sin dirimirse, confundida con la asistencialidad debida a las víctimas. En realidad, como dicen Quijano (2006: 20) y

\footnotetext{
${ }^{26}$ Cfr. el monográfico "A diez años del informe de la CVR" (VV. AA., 2013), donde se hace un balance.
} 
Pajuelo Teves (2006:73-74), ante esta relativa incapacidad de promocionar la plurinacionalidad, se observa únicamente una dirección centrífuga o étnicamente reclamante en las comunidades amazónicas, con la formación de la Coordinadora de Organizaciones Indígenas de la Cuenca Amazónica (COICA), comenzando la historia reciente de los movimientos indígenas andino-amazónicos; después, merced a las crisis de las organizaciones campesinas frente a las inconclusas reformas agrarias, y a los procesos acaecidos en Bolivia y Ecuador, las comunidades campesinas enfrentadas a multinacionales han retomado una identidad indígena capaz que pueda actuar en la forma de nuevos movimientos políticos de fuerte base identitaria. Los trabajos de la CVR, que negaban el conflicto étnico, obran en torno a considerar la dejadez del Estado en que tiene a buena parte de su población, así como a la reparación de los excesos y abusos de un sistema democrático inmerso en conflictividad armada, interna y por ende social. Aunque ciertamente el Informe final certifica y denuncia las desigualdades sociales y étnicas en el Perú, estructurales, diríamos, no permite establecer la apertura de una crítica etnocultural. De ahí su monumentalidad nacional unificada en diferentes programas políticos. Las Comisiones de la Verdad, como describe Laplante (2007: 128 ss.), van encaminadas, supuesta y en buena parte baldías, a satisfacer las expectativas de justicia de las víctimas. El beneficio individual y colectivo, catárquico, sigue estando en una esfera psicosocial que de algún modo deberá incidir en la reconstrucción de las demandas identitarias regionales y étnicas. Pero la víctima política (nacional) desactiva a la víctima étnica (histórica), de mayor problema. Dado que ninguno de los dos grupos terroristas del conflicto armado peruano detentaron o se arrogaron la defensa étnica (más bien la combatieron fuertemente) ${ }^{27}$, el etnocacerismo nacionalista de Humala (Ostrowska 2010), o la asunción del supuesto multiculturalismo político de Alejandro Toledo (Valdivia, Benavides y Torero 2007: 625 ss.), mal podrían estar llamados a esta función. Porque, sobre todo, a diferencia de la vitalidad de las exigencias pluriétnicas en Bolivia y quizá Ecuador, la transformación de indio a campesino aconteció preferentemente en el Perú a pesar de la fuerza moderada del indigenismo, un asunto propio de la lucha de clases (Ossio 2006); o como resultado de la combinación de factores como las exigencias del neoliberalismo, la violencia interna y la identificación clasista (Sundström 2010). ¿Es por esta razón que el Informe de la CVR no ha producido demandas étnicas? Sundström cita el conflicto interno (que llama Guerra civil, loc. cit.: \4.3, siguiendo la concepción de Stern, 1998) como una de las razones, la cual puede explicarse, por otra parte, como lucha de clases. La propia CVR cierra el conflicto en términos sociales. El Informe no ha querido ni podido alimentar las reivindicaciones étnicas en el Perú, dado que es un instrumento para la reconciliación nacional y la cohesión integrativa (Theidon 2004). De la afirmación: "La CVR ha podido apreciar que, conjuntamente con las brechas socioeconómicas, el proceso de violencia puso de manifiesto la gravedad de las desigualdades de índole étnico-cultural que aún prevalecen en el país. Del análisis de los testimo-

\footnotetext{
${ }^{27}$ Degregori (Degregori et al., 1992: 417-418) entiende que atribuir bases ideológicas andinas a los grupos terroristas del conflicto armado peruano son errores de la proyección orientalista de investigadores nacionales (recordemos el caso Uchuraccay; Aunque Ossio (2006) persiste en explicar las bases mesiánicas andinas de Sendero Luminoso) y extranjeros. No obstante, queda pendiente comprender las exigencias étnicas como ideologizadas.
} 
nios recibidos resulta que el 75 por ciento de las víctimas fatales del conflicto armado interno tenían el quechua u otras lenguas nativas como idioma materno" (CVR, Informe Final, Conclusiones), matizada por el Prefacio (CVR 2003, Prefacio; y CVR 2008: 4) que niega el conflicto étnico, no se desprende otra cosa.

\section{LÍMITES DE LA REPRESENTACIÓN CIENTÍFICA}

Rodríguez (2011) repasa la relación entre testimonios y discurso experto en las Comisiones de la Verdad, aplicándose al caso peruano. Quizá con un itinerario inverso, comienza desde el planteamiento de una abogada entrevistada que se preguntó en 2006 si lo escuchado y visto en el proceso de la CVR en Perú era "la voz de los testimonios" o una "lectura" de los mismos como el trabajo "de una comunidad intelectual analizando un proceso" (social) (loc. cit.: 589). Rodríguez parte de las CV como estructuras estandarizadas (Wilson 2011) que trabajan dentro de una "lógica representacional" (régimen de justicia) para la denuncia y acusación (siguiendo a Boltanski 2007) de los hechos perpetrados que atentan contra el Estado, la ciudadanía y los Derechos humanos. Sin este mecanismo, como advirtiera Primo Lévi, se caería en una "crisis de representación", confundiendo y pervirtiendo, sin referentes de justicia (incertidumbre referencial), víctimas y victimarios. Es así que Rodríguez (loc. cit.: 590) entiende cómo las CV tratan de evitar esta crisis de la representación.

Pero, ¿cuál es la legitimidad de un Estado comprometido como victimario?; y, en otro orden subsiguiente al trabajar adentro del engranaje estatal, ¿cuál la de las ciencias sociales orgánicas? (Degregori, 2003, como autor significativo al encontrarse críticamente adentro y afuera). La "lucha ideológica" que se daría dentro del análisis e interpretación de los hechos no tutelados, podría ser, en algunos casos, determinantemente necesaria. Se contestará a esto distinguiendo el caso peruano de otros en los que el Estado sí era victimario ${ }^{28}$. La solvencia de la CVR, y con ella la de las ciencias sociales, debería evitar esa crisis de representación, que de todas formas era del mismo Estado (Klarén 2007), y reducir el ruido que las diferentes narrativas de la lucha ideológica estarían causando, en espacial con respecto a las interpretaciones del fenómeno senderista: que fue explicado por distintos sectores como elemento ajeno y exterioridad a las comunidades andinas, y sin demandas étnicas (Degregori 1992: 417418). Sin embargo, pese a los esfuerzos (o disputas) al interior de la Comisión, parece obvio que el Informe fracasa en dar una coherente descripción de la realidad debido a las dificultades de conciliar posiciones disciplinarias o individuales distintas. Tanaka (2013) responde a por qué el Informe de la CVR no logró una coherencia explicativa en los distintos elementos estructurales e históricos de la violencia: oscilando entre interpretaciones contradictorias, la función última de la CVR recaía sobre

\footnotetext{
${ }^{28}$ Rodríguez (loc. cit.: 594) entiende que el trabajo de la CVR consistió, entre otras cosas, en asegurar por los hechos la diferencia entre actores armados subversivos y la sociedad civil desarmada; haciendo singular el caso peruano porque "por primera vez una fuerza insurgente de izquierda [en el contexto latinoamericano] practicó sistemáticamente la violencia contra la población civil igualando, y quizá sobrepasando, a la practicada por el Estado" (citando a Basombrío, 1998: 426; aspecto que corrobora el propio Informe de la CVR, 2003, Conclusiones generales: 317 ).
} 
la dignificación de las víctimas. Estimar las "tecnologías del testimonio" y el papel que en ellas juega el derecho y las Ciencias sociales sí unificó en el método a la CVR. Si en torno a la CV sudafricana surgió una verdad enfrentada a una verdad producida institucionalmente, la legitimidad de la verdad en la CVR peruana se confió a la labor científica (hechos, condiciones, participantes) del derecho y las ciencias sociales ${ }^{29}$, y su capacidad de trabajar con las informaciones derivadas de los testimonios y estudios de caso (Rodríguez 2011: 591) ${ }^{30}$. Este "discurso experto", por tanto, reconstruye los hechos auxiliados por las disciplinas científicas y sociales, y se abre más ampliamente que a las limitaciones legalistas de los Derechos humanos como operatividad jurídica. De todas formas, y aunque este análisis se ponga en el contexto de la construcción de los "marcos de interpretación dominantes", sí puede encontrarse problema en sociologizar la explicación de los hechos. Desde luego algo positivo ante las limitaciones de un estricto legalismo (no humanista ni como servicio público y social); sin embargo, y lejos de consideraciones objetivistas estériles, sociologizar «el conflicto" no escapa a críticas de la construcción de la disciplina. Pero ni esta solución ni tampoco la función de la CVR de trabajar por una memoria unificada y ponderada frente a la fragmentación de las memorias felices/infelices (Portocarrero 2004), heridas (Degregori 2004 b; Portocarrero, 2004) o distintas otras memorias y contra-memorias (Klarén 2007), parece capaz de abandonar, pese a la solvencia intelectual y las prevenciones éticas, un cierto esencialismo. Esencialismo andino propio, útil históricamente hablando en la elevación de la monumentalidad nacional criolla; que no parece solventarse adecuadamente bajo el temor de abrirse a la plurinacionalidad o la escisión. Si esto fuera así, la estrategia unificadora (y lo es por el simple hecho de su objetivo convivencial y de reconciliación nacional) caería en las limitaciones de su propio horizonte de representación, de sus propias posibilidades, víctima de su estrategia. Cuando Rodríguez escribe: "[Se instauró con el tiempo] una narrativa que reflejaba la exteriorización no tanto de la violencia como sobre todo de los elementos político-ideológicos del espacio comunitario andino; Se establece así una dicotomía entre el adentro pacífico, apolítico, de las comunidades campesinas vs. el afuera ideologizado y violento de los terroristas" (loc. cit.: 592), se pasa paulatinamente de entender un Estado victimario a un Estado-Nación (sumando las comunidades andinas masacradas como parte más débil y no integrada) víctima del terrorismo que en resistencia legítima desmantela finalmente la estructura política y militar del terrorismo. En este proceso fue necesario discernir entre los sectores armados (insurgencia terrorista) y población civil inerme. Es en esta pugna en la que interviene la CVR, condicionada por sus contornos políticos. El Informe de la CVR ampliará los linderos políticos de interpretación al asumir la oportunidad histórica de dar la voz a las ciudadanías

\footnotetext{
${ }^{29}$ "La CVR entiende por verdad el relato fidedigno, éticamente articulado, científicamente respaldado, contrastado intersubjetivamente, hilvanado en términos narrativos, afectivamente concernido y perfectible, sobre lo ocurrido en el país en los veinte años considerados por su mandato" (así la CVR; tomado de González, 2011: 149).

${ }^{30}$ Cita el Informe final, donde se asume el socorro de expertos y métodos científicos actualizados para "garantizar la mayor objetividad posible", tanto en el análisis técnico de restos forenses, el derecho y la criminología, como en la interpretación y contextualización histórica y social de los hechos: antropólogos, sociólogos, psicólogos e historiadores; dando "así un respaldo científico al relato éticamente articulado" (CVR, 2003, Introducción: 32-33).
} 
subalternas, amortiguando la crisis de representación al consolidar sus tesis por medio de la legitimidad de una investigación a partir de los testimonios (loc. cit.: 592; citando a Castillejo 2007: 78). Adentro de la CVR y el Informe, como también en las Audiencias públicas, la "verdad histórica" (y la interpretación contextual) se sobrepuso a la "verdad jurídica", otorgando voz, dignidad y visibilidad a la ciudadanía despreciada secularmente. En este sentido, la CVR provoca un "proceso de desestabilización de las relaciones de poder, históricamente producidas, entre Estado y comunidades campesinas andinas" (loc. cit.: 594). Pero quizá, más bien, un balance, aunque la refundación del estado pudiera ser desde posiciones unificadoras. Seguramente, la verdad jurídica recaiga sobre el aparato administrativo estatal previo, que dispone de ella sin reconocer otras, con no ser tampoco homogénea; por contraposición a una verdad sociohistórica memorial que de todas formas no acaba de identificar unas otras instancias y tradiciones jurídicas, étnicas por ejemplo. Ya mencionamos la regulación de las rondas campesinas como elemento de derecho consuetudinario asimilado a la personería jurídica. Pero es necesario recordar que de todos modos estas cuestiones son producto más bien de la supuesta o manifiesta incapacidad de la CVR para procurar transformaciones profundas del aparato estatal y la reconfiguración nacional. Porque las recomendaciones del Informe recogen explícitamente lo siguiente: "Uno de los sectores más duramente golpeados por la violencia y el abandono son los pueblos indígenas. Es recomendable que el Estado promueva el reconocimiento y fortalecimiento de los derechos específicos de los pueblos indígenas y comunidades en el marco jurídico nacional, e incluirlos de manera importante en el proceso de reforma constitucional, con la finalidad de brindarles una protección jurídica justa y legítima como sujetos de derechos y reafirmar la diversidad y pluralidad de la nación peruana” (t. IX. Recomendaciones, $₫ 2.1$. Reformas institucionales; Valer-Bellota 2008: 225 ss.). Las recomendaciones subsiguientes se refieren a la inclusión de derechos individuales y colectivos en el texto constitucional; la definición de Perú como Estado multinacional, pluricultural multilingüe, y multiconfesional; practicar la interculturalidad como política de Estado; reconocimiento legal de las organizaciones comunales; reconocimiento de tierras-territorios tradicionales inalienables; "Derecho y administración de justicia indígena de acuerdo a los derechos humanos y acceso a la justicia ordinaria con juzgados especializados en materia indígena"; y "Reconocimiento de mecanismos tradicionales de justicia alternativa" (ibídem). ¿Cuál es el modelo de Estado-nación que habita aquí, o que de esto se desprende? El integrativo de derechos o de instituciones indígenas desde un reconocimiento previo de ciudadanía, estatuto al que se ha llegado a través de la consideración de víctima excluida. Esta ganancia no es pues de principio, sino correlativa a un estado crítico que lucha por reconceptualizarse sin perder un "sentido ordenado" en modelos democráticos concretos con recursos compensatorios como los Derechos humanos.

El equilibrio de la CVR tuvo lugar eminentemente en el campo, sobre el terreno, como adelantábamos, donde las narrativas se disputan sobre las voces populares y politizadas/despolitizadas, y donde era necesaria una labor de asimilación victimal. Atendiendo al estatuto de los testimonios y sus discursos en el contexto de la denuncia: ciertamente, la CVR tuvo que "gestionar una relación compleja" con el Estado e incluso con las comunidades, para certificar su implicación en el conflicto, autoría y responsabilidad (Rodríguez 2011: 595). La estrategia de las víctimas fue la de supri- 
mir discursos y compromisos anteriores y plegarse a la interpretación oficial de la exterioridad de Sendero asumida, aunque con matices, por la CVR. Procesaron las narrativas así adaptándose a ellas, explicando la irrupción de Sendero en una paz comunitaria en la que la movilización campesina era prácticamente imposible dada su concentración en la cotidianidad agropecuaria, el analfabetismo, etc. Las comunidades aparecen así como espectadoras de la política terrorista, y leales al Estado. Esta "inocencia política" de las comunidades es aceptada por hacer coincidir la verdad histórica con la verdad jurídica; si bien las comunidades, a la expectativa de las posibles reparaciones, silenciaron a la CVR los discursos políticamente comprometidos anteriores, apartando a los testigos que habían participado activamente en Sendero, etc. (ibid.; citando a Laplante y Theidon 2010: 303); la actitud estratégica de los uchuraccaínos retornados ante la Comisión de Vargas Llosa habría sido similar (Del Pino 2003). Esta política de lo silenciado e implícito configura el paso de victimarios a víctimas, resultado del "contexto de la denuncia" más que de una verdad de hecho (Rodríguez 2011: 596). Asimismo, el resultado de los trabajos intelectuales en estos procesos asume el estatuto del testimonio. Rodríguez se pregunta por la mejor forma de trabajar desde las ciencias sociales considerando que el testimonio revela más el contexto de la denuncia que un "hecho de violencia". Ciertamente, esto no supone invalidar ni la dignidad de los hablantes ni la validez de sus denuncias. Más bien interpela acerca de la forma de trabajar. Rodríguez entiende que lo propio es descentrar el discurso experto para "colocarse como una parte más dentro de una variedad de actores y sus subjetividades políticas" (loc. cit.: 596). Evitando confrontar la vOZ de los testimonios, que no deja de ser política. Critica el exceso de las ciencias sociales que crece y construye a partir de la extracción (Castillejo 2005: 50-51), de forma positivista, construyendo la categoría de "Víctima". Sin embargo, en el contexto de las CV y las CVR, las ciencias sociales están llamadas a documentar hechos y contextos de interpretación que reequilibren al menos las fuerzas de las narrativas disponibles; además de otorgar legitimidad a las Comisiones (Rodríguez, loc. cit.: 598). Lo que acaba en facilitar y argumentar la pluralidad de memorias campesinas, facultando a la antropología como versión posible (Del Pino 2003). Todo lo cual conduce a preguntarse por los límites de la legitimidad científica: que pasan por averiguar el sujeto (colectivo) al que estaba dirigido el Informe de la CVR. En efecto, se ve en la labor de la CVR la construcción de un "espectador moral" (loc. cit.: 599; siguiendo a Boltanski 2007: 90-91), preparando a un audiencia con la habilitación de los testimonios públicos y el Informe: la descripción del sufrimiento del desdichado requiere del espectador que lo observa y escucha (pensemos en Derrida o Ricoeur). Sin embargo, Rodríguez subraya cómo el Informe de la CVR denunció precisamente la "ausencia" del espectador moral ante el sufrimiento de una buena parte de la población, secularmente ignorada. El Informe constata estas brechas, por lo que la vergüenza nacional produce el espectador moral, aprestado a la escucha. Todo ello bajo la premisa de las negociaciones recíprocas de lo contado y lo admitido: sobre todo, al cabo de asegurar la despolitización del ingenuo e inocente campesino, el silenciamiento de parte de la historia, y la asunción de la violencia como opuesta a un futuro democrático. La esencialización no problemática de los héroes patrios es el reverso de esta función (Alfaro Rotondo s. f.).

Sin embargo, la CVR no reconoció conflictos étnicos (atribuir etnicismo a Sendero 
lo hubiera corroborado), explicando y "amortiguando" las narrativas oficiales que ponían a salvo el Estado republicano. La crítica final, a nuestro entender, pasa por repetir las amargas palabras de Iván Degregori sobre los "pequeños holocaustos", fehacientemente documentados y entregados al gobierno por la CVR, ante lo cual "no pasa nada, o pasa muy poco... Muy poco sobre justicia, o sobre las reparaciones simbólicas..., casi nada sobre las profundas reformas institucionales que son indispensables para que esta historia no se repitan; y su propuesta de refundar el Estado-nación. La antropología vuelve aquí a recordar/rehabilitar continuidades memoriales (sojuzgadas y nacionales) y demandar reequilibrios políticos. Sin embargo, apenas puede escapar a los modelos referenciales de organización política del Estado, marco (pero también campo) insoslayable de su labor intelectual.

Para concluir, y retornando al principio, bien podemos preguntarnos, en esa fraternidad disciplinaria que mira no obstante a un país de observación con artefactualidad lectora y escritural, sobre la verticalidad del escribiente o sus sensibilidades, proporcionadas por sus violencias analíticas. Parece evidente que la antropología se cuela en distintos grados y formas en estos textos y contextos, con diferente rigor en su práctica discursiva. No son lo mismo, ni lo pretendemos, las actitudes insuficientes e imperfectas, o quizá bastardas, de la Comisión de Uchuraccay, las poses del rendimiento político de la esposa antropóloga de cierto presidente del Perú (que parece no poder funcionar sola), o la labor dedicada y profesional de la antropología académica o institucional (en la CVR por ejemplo), o por fuera de ella. Queremos reproducir el argumento de C. Blondet y E. González (Degregori et al., 1996: 13):

Los textos son, de paso, una reivindicación de la Antropología. Desde el poder se trató de descalificar con frecuencia a quienes criticaban la política antisubversiva "desde sus escritorios". Nada más alejado de los escritorios que la Antropología, disciplina que hizo del trabajo de campo rito de pasaje y viaje iniciático, privilegiando, muchas veces de manera exagerada, el "estar alli", en el lugar de los acontecimientos. En este volumen la exageración se convierte en mérito en el caso de José Coronel y Ponciano del Pino, profesores de la UNSCH que no sólo pasaron en Ayacucho los más duros años de la violencia sino que, como también lo hicieron muchos otros profesionales ayacuchanos, tuvieron la presencia de ánimo para salir al campo, y hoy nos presentan lo que podríamos llamar "etnografías a salto de mata" de la provincia de Huanta y del valle del río Apurímac en los tiempos de violencia. La investigación se desarrolló en condiciones sumamente adversas, pero el resultado es sin duda alguna un aporte para comprender la historia peruana de estos años difíciles.

Sin embargo, cabe preguntarse si es sólo el rigor o la autoridad lo que delimita los contornos de lo que es o no es antropología, entendiendo bien que el estudio de la violencia no es meramente un campo altamente meritorio como el que otrora fue la etnografía en lugares remotos. La legitimidad de las antropologías, como de la intelectualidad, es algo que debe debatirse, y pueden estar comprometidas ${ }^{31}$. A nuestro juicio, además de la crítica, habrá que habilitar una ética del sujeto victimado "na-

\footnotetext{
${ }^{31}$ Del Pino (2003: s. p.), por ejemplo, narra cómo al volver a Uchuraccay tuvo no sólo que ganarse la confianza de los retornados, sino "diferenciarse" del primer momento del conflicto y de los que habían llegado interrogando sobre la matanza. Tuvo que desplegar estrategias distintas para ofrecer una versión entre tantas, sin asumir un papel de autoridad.
} 
rrado" y la memoria, con ser tan insuficiente, la decolonialidad del saber y la hermenéutica del texto autoral, aspecto que de todos modos superan muchos autores y trabajos mencionados aquí.

\section{BIBLIOGRAFÍA CITADA}

Alfaro Rotondo, Santiago. S. f. "Héroes gamonales: en el Abismo de Todos, el Nosotros de Algunos", en red.pucp.edu.pe/ridei/wp-content/uploads/biblioteca/090519.pdf

Andreu, Alicia. 2002. "El testimonio peruano oral y las Ciencias Sociales: una problemática postmoderna". Copé, vol. XIII, no. 30: 8-13.

Andrews, Molly. 2007. "Pero si no he acabado... tengo más que contar': Las limitaciones de las narraciones estructuradas de los testimonios públicos". Antípoda 4: 147-149.

Basombrío, Carlos. 1998. "Sendero Luminoso and Human Rrights. A Perverse logic that Captured the Country", en Steven Stern (ed.). Shining and Other Paths. War and Society in Peru 1980-1995. Durham: Duke U. Press.

Bolívar, Ingrid Johana, y Alberto Flórez. 2004. “La investigación sobre la violencia”. Revista de Estudios Sociales 17: 32-41.

Boltanski, Luc. 2007. La souffrance à distance. Paris: Gallimard.

Burga, Manuel. 2014. "Historia y antropología en el Perú (1980-1998): tradición, modernidad, diversidad y nación". www.fas.harvard.edu/ icop/manuelburga.htmlý

Burt, Jo Maria. 2010. "Los usos y abusos de la memoria de María Elena Moyano". A contra corriente 7(2): $165-209$.

Casalino, Carlota. 2008. Los héroes patrios y la construcción del Estado - nación en el Perú (siglos XIX y $X X)$. Tesis doctoral. Lima: UNMSM.

Castillejo, Alejandro. 2005. "Las texturas del silencio: violencia, memoria y los límites del quehacer antropológico". EMPIRIA. Revista de Metodología de las Ciencias sociales 9: 39-59.

Castillejo, Alejandro. 2007. "La globalización del testimonio: historia, silencio endémico y los usos de la palabra". Antípoda 4: 76-99.

Comisión de la Verdad y Reconciliación. 2003. Informe Final. Lima.

Comisión de la Verdad y Reconciliación. 2003 b. "El impacto de las audiencias públicas en los participantes". Lima.

Comisión de la Verdad y Reconciliación. 2008. Hatun Willakuy: Versión abreviada del Informe Final de la Comisión de la Verdad y Reconciliación, $2^{\mathrm{a}}$ ed., Lima.

Cornejo-Polar, Antonio. 1990. "El comienzo de la heterogeneidad en las literaturas andinas: voz y letra en el diálogo de Cajamarcan. Revista de crítica literaria latinoamericana 33: 155-207.

Cotler, Julio. 1993. Descomposición política y autoritarismo en el Perú. Lima: IEP.

Cuya, Esteban. 1996. "Las Comisiones de la Verdad en América Latina”. KO'AGA ROÑE’ETA Serie III, http://www.derechos.org/koaga/iii/1/cuya.html

Das, Veena. 2008. "Wittgenstein y la antropología", en Franciso A. Ortega Martínez (ed.), Veena Das: Sujetos del dolor, agentes de la dignidad. Bogotá. Universidad Nacional de Colombia, CES.

Das, Veena y Deborah Poole. 2008. "El estado y sus márgenes: etnografias comparadas". Cuadernos de antropología social 27: 19-52.

De la Cadena, Marisol. 2001. "The marketing of El Cholo Toledo". NACLA Report on the Americas 34 (6): 20-21.

De la Cadena, Marisol. 2007. «La producción de otros conocimientos y sus tensiones: ¿De la antropología andinista a la interculturalidad?", en Carlos Ivan Degregori y Pablo Sanvoval (comps.), Saberes periféricos. Ensayos sobre la antropología en América Latina: 107-152. IFEA-IEP.

Del Pino, Fermín. 2008. "De las Crónicas de Indias a Malinowski, o de la influencia (menospreciada) de los textos en el trabajo de campo". Revista de Dialectología y Tradiciones Populares LXIII (1): 17-36.

Del Pino, Ponciano. 2003. "Uchuraccay: memoria y representación de la violencia política en los Andes", en Elizabeth Jelin (comp.). Luchas locales, comunidades e identidades 11-62. Madrid: Siglo XXI.

De Vivanco, Lucero. 2011. "El capítulo PCP-SL en la narrativa de Mario Vargas Llosa”. Revista chilena de Literatura, $\mathrm{n}^{\circ}$. 80: 5-28. 
Degregori, Carlos Iván. 1990. El surgimiento de Sendero Luminoso: Ayacucho 1969-1979. Lima: IEP.

Degregori, Carlos Iván. 1992. "Campesinado andino y violencia: balance de una década de estudios", en Carlos Iván Degregori, Javier Escobal y Benjamín Marticorena (eds.), Perú: el problema agrario en debate: 413-439. Lima: Sepia.

Degregori, Carlos Iván. 1997. "After the Fall of Abimael Guzmán”, en Maxwell A. Cameron y Phiphilp Mauceri (eds.), The Peruvian Labyrinth: Polity, Society, Economy: 179-191. Philadelphia, PA: Pennsylvania State UniversityPress.

Degregori, Carlos Iván. 2003. "Perú: identidad, nación y diversidad cultural". Territorio, cultura e bistoria. Lima: Cooperación Alemana al Desarrollo/Prom Perú/Instituto de Estudios Peruanos: 212-228.

Degregori, Carlos Iván. 2004 a. "Desigualdades persistentes y construcción de un país de ciudadanos". Cuestión de Estado. 33-34: 24-31.

Degregori, Carlos Iván. 2004 b. "Heridas abiertas, derechos esquivos: reflexiones sobre la CVR", en Raynald Belay et al. (dirs.), Memorias en conflicto: aspectos de la violencia política contemporánea: 75-85. Lima: IFEA.

Degregori, Carlos Iván, José Coronel, Fermín Del Pino, y Orin Starn. 1996. Las rondas campesinas y la derrota de Sendero Luminoso. Lima: IEP/Universidad Nacional de San Cristóbal de Huamanga.

Degregori, Carlos Iván, y Pablo Sanvoval. 2008. "Dilemas y tendencias en la antropología peruana: del paradigma indigenista al paradigma intercultural", en Carlos Iván Degregori, y Pablo Sanvoval (comps.), Saberes periféricos. Ensayos sobre la antropología en América Latina: 19-72. Lima: IFEA-IEP.

Espinoza, Esther. 2003. "Con nombres propios. Análisis del testimonio de Liz Valdez ante la Comisión de la Verdad", en Gonzalo. Espino Relucé (comp.), Tradición oral, culturas peruanas -una invitación al debate-: 217-224. Lima: UNMSM.

Flores Galindo, Alberto. 1993. Buscando un Inca. Identidad y utopía en los Andes. México: Consejo Nacional para las Ciencias y las Artes-Grijalbo.

Flores Galindo, Alberto. 2001. Los rostros de la plebe. Barcelona: Crítica.

Garretón, Franciska, González, Marianne, y Silvana Lauzán. 2011. Políticas públicas de Verdad y Memoria en 7 países de América Latina (Argentina, Bolivia, Brasil, Chile, Paraguay, Perú y Uruguay). Santiago de Chile: Programa Derechos Humanos y Democracia, Centro de Derechos Humanos-Facultad de Derecho, Universidad de Chile.

González, Mariella. 2011. "La ritualización de la reconciliación y reparación en espacios públicos: "Un entierro digno para Putis"m, en Diana Flores et al., Nuevas miradas al Perú contemporáneo. Movimientos sociales, identidad y memoria: 141-174. Lima: Programa Democracia y Transformación Global.

González Echevarría, Roberto. 2000. Mito y archivo. Una teoría de la narrativa latinoamericana. México: Fondo de Cultura Económica.

Guerrero, Andrés. 2000. "El proceso de identificación: sentido común ciudadano, ventriloquia y transescritura", en Andrés Guerrero (comp.), Etnicidades: 9-60. Quito: FLACSO, ILDIS.

Jelin, Elizabeth. 2001. Los trabajos de la memoria. Madrid: Siglo XXI.

Joseph, Gilbert y Daniel Nugent (eds.). 1994. Everyday Forms of State Formation. Revolution and the Negotiation of Rule in Modern Mexico. Durham: Duke U. Press.

Klarén, Peter. 2007. "El tiempo del miedo’ (1980-2000), la violencia moderna y la larga duración en la historia peruana", en Anne Pérotin-Dumon (dir.), Historizar el pasado vivo en América Latina. http:/ /www.historizarelpasadovivo.cl/downloads/klaren.pdf

Korsbaek, Leif. 2009. La ronda campesina en el Perú. Los ciudadanos contra el estado. México: Mano Vuelta.

Landa Vásquez, Ladislao. 2010. "José María Arguedas nos engañó: Las ficciones de la etnografía". Revista de Crítica Literaria Latinoamericana 72: 129-154.

Laplante, Lisa. 2007. "Después de la verdad: demandas para reparaciones en el Perú poscomisión de la verdad y reconciliación". Antípoda. Revista de Antropología y Arqueología 4: 119-145.

Laplante, Lisa y Kimberly Theidon. 2010. "Commissioning Truth, Constructing Silences. The Peruvian Truth Commission and the Other Thruths of "Terrorists"', en Kamari Maxine Clarke y Mark Goodale, Mirrors of Justice. Law and Power in the Post-Cold War Era: 291-315. N. Y.: Cambridge U. Press.

López Maguiña, Santiago. 2003. "Arqueologías de una mirada criolla: el informe de la matanza de Uchuraccay", en Maritza Hamann, Santiago López Maguiña, Gonzalo Portocarrero y Víctor Vich (eds.), Batallas por la memoria. Antagonismos de la promesa peruana: 257-275. Lima: Red para el Desarrollo de las ciencias Sociales en el Perú.

Lund, Julius. 1999. "El doble estándar de Vargas Llosa en su visión de la historia", en La langue, les signes et les êtres: actes du colloque de l'Institutd'Etudes Romanes de l'Université de Copenhague, le 3 octobre 1998. Etudes Romanes 44: 161-172. 
Martín Sánchez, Juan. 2005. "Hatun Willakuy, importancia del relato en la política. Comentarios al Informe final de la Comisión de la Verdad y Reconciliación del Perú". Nueva sociedad nº 197: 54-68.

Mayer, Enrique. 1991. "Peru in Deep Trouble: Mario Vargas Llosa's "Inquest in the Andes" Reexamined". Cultural Anthropology, vol. 6, no. 4: 466-504.

Mesclier, Evelyne. 2001. "De la complementariedad a la voluntad de aplanar los Andes: representaciones de la naturaleza y pensamiento económico y político en el Perú del siglo XX". Bulletin de l'IFEA 30(3): 541-562.

Mignolo, Walter. 1995. The Darker Side of the Renaissance: Literacy, Territoriality and Colonization. Ann Arbor: The University of Michigan Press.

Molinié, A. 2004. "Theresurrection of the Inca: the role of Indianrepresentations in theinvention of thePeruviannation". History and Anthropology 15(3): 233-250.

Muñoz, Ismael, Maritza Paredes y Rosemary Thorp. 2009. "Acción colectiva, violencia política y etnicidad en el Perú", en Ismael Muñoz Portugal, Acción colectiva, desigualdad y conflicto en la sociedad peruana: Una aproximación: 9-54. Lima: PUC.

Oelschlegel, Adrián. 2006. "El Informe final de la Comisión de la Verdad y Reconciliación en el Perú. Un resumen crítico respecto a los avances de sus recomendaciones". Anuario de Derecho Constitucional Latinoamericano XII, t. II: 1335-1368.

Orlove, Benjamín. 1991. "La violencia vista desde arriba y desde abajo: narrativas oficiales y campesinas de encuentros conflictivos en la Sierra sur del Perú", en Enrique Urbano (comp.). Poder y violencia en los Andes: 237-259. Cuzco: Centro de Estudios Regionales Andinos Bartolomé de Las Casas.

Ortega, Julio. 1986 [2007]. Adiós Ayacucho. Lima: UNMSM.

Ortiz Fernández, Carolina. 2004. "El testimonio, ¿un acto de poder? Sobre el proceso de producción e interpretación del testimonio". Investigaciones sociales 13: 245-252.

Ossio, Juan M. 2006. "Multiculturalidad e indianismo en el Perú". Diversidad y reconocimiento. Aproximaciones al Multiculturalismo y a la Interculturalidad en América Latina. Suplemento del Boletín Diario de Campo 79-88.

Oxfam GB. 2004. Mapeo de las organizaciones de afectados por la violencia política en el Perú. Lima.

Ostrowska, Joanna. 2010. "Hombre andino contra hombre occidentalizado: el etnocacerismo de los Humala". Itinerarios 11: 85-101.

Pajuelo Teves, Ramón. 2006. Participación política indígena en la sierra peruana: una aproximación desde las dinámicas nacionales y locales. Lima: IEP.

Plasencia Soto, Rommel 2011. "¿Caminos intrincados? La narrativa de Vargas Llosa y las ciencias sociales". Nómadas. Revista Crítica de Ciencias Sociales y Jurídicas 30 (2): 123-145.

Poole, Deborah y Renique, Gerardo. 1992. "Perdiendo de vista al Perú. Réplica a Orin Starn". Allpanchis 23(39): 73-92.

Portocarrero, Gonzalo. 2004. "Perú, el país de las memorias heridas: entre el (auto)desprecio y la amargura", en Reynald Belay et al. (dirs.), Memorias en conflicto: aspectos de la violencia política contemporánea 35-49. Lima: IFEA.

Quijano, Anibal. 2006. "Estado-nación y movimientos indígenas en la región Andina: cuestiones abiertas". OSAL, Observatorio Social de América Latina 19: 15-24.

Quiroz, Víctor 2006. "Ficciones de la memoria. La novela del conflicto armado interno (1980-2000) y las tensiones de la modernidad colonial en el Perú". El hablador, nº 10: s. p.

Quispe-Agnoli, Rocío. 2006. La fe andina en la escritura: resistencia e identidad en la obra de Guamán Poma de Ayala. Lima: UNMSM.

Quitián Peña, Esteban. 2007. "El conflicto entre letra y voz y los límites de la representación", en María Teresa Garzón Martínez y Nydia C. Mendoza Romero (Eds.), Mundos en disputa. Intervenciones en Estudios culturales: 145-204. Bogotá: Pontificia Universidad Javeriana. Pensar. Instituto de Estudios Sociales y Culturales.

Raymond, Christopher y Moisés Arce. 2011. "The politicization of indigenous identities in Peru". Party Politics, s. d.: 1-22.

Ribeiro, Darcy. 1977. Las Américas y la civilización. México: Ed. Extemporáneos.

Ricoeur, Paul. 1996. Tiempo y narración. Tomo III. México: Ed. Siglo XXI.

Ricoeur, Paul. 2003. La Memoria, la Historia, el olvido. Madrid: Trotta.

Rodríguez Maeso, Silvia. 2011. "Testimonios, discurso experto y comisiones de la verdad: el contexto de la denuncia". Política y Sociedad 48 (3): 587-602.

Roncalla, Fredy Amílcar. 2002. "iHablan los Apus?". Quehacer 137: s. p. 
Rottenbacher, Jan Marc y Agustín Espinosa. 2010. "Identidad nacional y memoria histórica colectiva en el Perú. Un estudio exploratorio". Revista de Psicología 28 (1):147-174.

Rowe, William. 1997. "La novela y los problemas de la historiografía en el Perú andino". Estudios. Revista de investigaciones literarias 10: 103-112.

Salazar, Claudia. 2008. "Narrativa y Memoria: la construcción del relato del horror en el Informe Final de la Comisión de la Verdad (Perú, 2003)». Espéculo. Revista de estudios literarios 39: s. p.

Saunders, Rebeca. 2008. "Lo que se pierde en la traducción: expresiones del sufrimiento humano, el lenguaje de los Derechos Humanos y la Comisión Sudafricana de Verdad y Reconciliación". Sur. Revista internacional de Derechos Humanos 9: 53-75.

Starn, Orin. 1991. "Missing the Revolution: Anthropologists and the War in Peru». Cultural Anthropology 6 (19: 63-91.

Starn, Orin. 1992. "Antropología andina, 'andinismo' y Sendero Luminoso". Allpanchis 23(39): 15-72.

Starn, Orin. 1994. "Rethinking the politics of anthropology: The case of the Andes land comments and reply]. Current Anthropology 35 (1): 13-38.

Stern, Steve J. (ed.). 1998. Shining and Other Paths. War and Society in Peru 1980-1995. Durham: Duke University Press.

Sundström, Björn. 2010. Etnicismo y el caso peruano. Tesis de grado. Stockholm: Stockholm University. Faculty of Humanities, Department of Spanish, Portuguese and Latin American Studies.

Tanaka, Martín. 2013. "Las ambiguedades del IF de la CVR en la explicación". Argumentos. 4. http:// revistaargumentos.iep.org.pe/articulos/las-ambiguedades-del-if-de-la-cvr-en-la-explicacion/

Tejero Tabernero, Laura. 2014. "Nosotros, las víctimas": violencia, justicia transicional y subjetividades políticas en el contexto peruano de recuperación posconflictom. Papeles del CEIC 1- 106: 1-30.

Theidon, Kimberly. 2004. Entre prójimos. El conflicto armado interno y la política de la reconciliación en el Perú. Lima: IEP.

Theidon, Kimberly y Peralta Quinteros, Enver. 2003. "Uchuraccay: La Política de la Muerte en el Perú". Ideele: Revista del Instituto de Defensa Legal no. 269: 27-31.

Valdivia, Néstor, Martín Benavides y Máximo Torero. 2007. «Exclusión, identidad étnica y políticas de inclusión social en el Perú: el caso de la población indígena y la población afrodescendiente», en Investigación, políticas y desarrollo en el Perú: 603-655. Lima: GRADE.

Valer-Bellota, Pavel H. 2008. "Etnografía constitucional del Perú: sociedad multicultural y tendencias del Derecho Constitucional", en Nuria Belloso Martín y Alfonso de Julios-Campuzano (coords.), ¿Hacia un paradigma cosmopolita del derecho? Pluralismo jurídico, ciudadanía y resolución de conflictos: 199-227. Oñati: IISJO.

Vargas-Salgado, Carlos. 2011. Teatro peruano en el periodo de conflicto armado interno (1980-2000): estética teatral, Derechos humanos y expectativas de descolonización. Tesis doctoral. University of Minnesota.

Vega Bendezú, Mauro. 2011. «Entre la utopía andina y la utopía republicana. Representaciones públicas en los Andes (algunas aproximaciones)", en Ignacio Peiró y Gustavo Alares (coords.), "Dossier: Pensar la Historia, celebrar el pasado". Jerónimo Zurita, no. 86: 99-130.

Verdesio, Gustavo. 2001. „Forgotten Territorialities. The Materiality of Indigenous Past». Neplanta. Viewsfrom South 2 (1): 85-114.

Vich, Víctor. 2002. El caníbal es el Otro. Violencia y cultura en el Perú contemporáneo. Lima: IEP.

Villarías-Robles, Juan José. 2008. "La antropología posmoderna: Una reflexión desde la etnohistoria peruanistan. Revista de Dialectología y Tradiciones Populares, Vol. LXIII, ํㅡㄹ 1: 37-74.

VV. AA. 2011. Monográfico "El legado de Carlos Iván Degregori”. Argumentos. 3.

VV. AA. 2013. Monográfico "A diez años del informe de la CVR". Argumentos. 4.

Wilson, Richard. A. 2001. The Politics of Truth and Reconciliation in South Africa. Legitimizing the PostApartheid State. Cambridge: Cambridge U. Press.

Zapata Velasco, Antonio. 2010. La Comisión de la Verdad y Reconciliación y los Medios de comunicación. Ayacucho y Lima. Lima: IEP. Documento de trabajo nº 158.

Fecha de recepción: 16 de marzo de 2014

Fecha de aprobación: 25 de junio de 2015 